\title{
VEGETACIÓN DESÉRTICA DEL VALLE DE CINTO
}

Rosario Zegarra Zegarra ${ }^{\prime}$

\author{
$R E S U M E N$
}

\begin{abstract}
En el presente trabajo de investigación se presenta los resultados de las observaciones in situ y estudios biosistemáticos de la vegetación desértica del fondo y los flancos del aislado y poco estudiado valle de Cinto, mayormente en las localidades de Callacazal, La Machorrita, La Cruz del Carzo, El Barrial, Chirontita y Matogroso.
\end{abstract}

El valle del Cinto se caracteriza por su extrema aridez, ausencia de lluvias, suelos francoarenosos y alta radiación solar durante todo el año. En el perfil panorámico de la vegetación desértica resalta la adaptación de árboles, de mediano tamaño de los géneros Prosopis, Acacia y Haplorhus. Estos árboles gracias a su profundo y desarrollado sistema radicular, parecen extraer agua de napas freáticas muy profundas, originado en muchos casos, a pesar de la aridez superficial, una abundante biomasa de ramas, hojas, flores y frutos. A la fecha se han estudiado e identificado para el valle de Cinto 58 especies de Fanerogamas, agrupadas en 53 géneros y 24 familias taxonómicas.

\section{A B S TRACT}

This research project shows the results of two years of wild plant botanical explorations and biosystematics studies on desertic species grow and expanded throughout valley of Cinto, Tacna, Perú, mainly in the localities of Callacazal, La machorrita, La Cruz del Carso, Barrial, Chirontita and Matogroso.

The Cinto valley climate is rated as desert climate, characterized by almost total lack of rainfall, high solar radiation and wide day -to- night temperature range, and sandy stratified soils of finer material. A panoramic view of the desertic vegetation reveals the high occurrence and adaptation of middle size trees from genera Prosopis, Acacia, and Haplorhus. These trees, thanks to their deep rout system absorb water from deep humid soil layers and display profuse green biomass, in spite of the extremely arid conditions. At present, a total of 58 plant Fanerogamic species has been studied and identified as native to this valley, all grouped in 53 genera and 24 taxonomic families.

\section{INTRODUCCIÓN}

Durante las recientes exploraciones botánicas y estudios biosistemáticos de la flora desértica de Tacna, se ha detectado una formación vegetal típica entre Puquio y Camiara de aproximadamente 100 hectáreas de superficie desértica constituida por atractivos Cactus columnares de la especie Neoraimondia arequipensis "Gigantón". Algunos ejemplares de esta especie se calcula que tienen más de 100 años, de un metro de diámetro y una altura hasta de 8 metros. Esta formación de Cactus debe conservarse por su gran valor ecológico y atracción turística (Foto 1).

Asimismo, en la quebrada árida de Gallinazos entre Shintari e llabaya se han identificado y estudiado por primera vez para el sur del Perú la especie Solanum pennellii (Lycopersicon pennellii),

I Doctora en Ciencias Biológicas y Docente Principal de Bótanica Agricola de la Facultad de Ciencias Agricolas. 
constituyendo una formación vegetal muy xerófita. Esta especie de flores amarillas y con tricomas glandulares es extremadamente resistente a sequia e insectos y constituye desde el punto de vista filogenético y taxonómico un eslabón entre el género Solanum (de la papa) y el género Lycopersicon (del tomate).

En el departamento de Tacna, la provincia de Jorge Basadre Grohmann es la segunda en extensión con $2928,72 \mathrm{~km}^{2}$. En ella se ubica el valle de Locumba $y$ en forma paralela y hacia el norte se ubica el valle de Cinto. Este valle se extiende desde cerca de la ciudad de Locumba a 559 m.s.n.m. hasta las vertientes occidentales de los Andes. Hasta el año de 1950 fue un valle próspero, frutícola por excelencia con tierras fértiles. Famoso por sus duraznos, vid y renombrados licores con llamativos envases, los cuales se exportaban hacia Europa. Actualmente se halla desertificado. Su clima es templado cálido con $\mathrm{T}^{\circ}$ máxima: $26.7 \mathrm{C}^{\circ}, \mathrm{T}^{\circ}$ mínima: $12,2^{\circ} \mathrm{C}, \mathrm{T}^{\circ}$ media: $19,2^{\circ} \mathrm{C}$. Precipitación fluvial escasa con periodos de total ausencia de lluvias, radiación solar muy alta entre 7 y 8 horas, suelo arcilloso, limoso y con grava.

La vegetación desértica de Cinto es herbácea, con pocas especies arbustivas y arbóreas pero que resaltan dentro del perfil panorámico de la vegetación del valle. Este trabajo se basa en el estudio in situ y en las colecciones efectuadas por la autora. La colección se realizó de acuerdo con técnicas convencionales. En esta publicación se enfoca en forma exclusiva los aspectos biosistemáticos de las principales especies arbóreas y arbustivas leñosas de las formaciones vegetales del valle de Cinto.

\section{DESCRIPCIÓN DE, LAS ESPECIES ARBUSTIVAS Y ARBOREAS}

\section{Haplorhus peruviana Engler "Jassi, molle, Carza".}

Árbol dioico, de 3-6 m de altura. Copa amplia. Tronco cilíndrico irregular, corteza fisurada, color café claro, ramas delgadas péndulas.

Hojas simples, alternas, verde giaucas, linear lanceoladas de $4-10 \mathrm{~cm}$ de largo, cortamente pecioladas. Inflorescencia: panículas cortas. Flores masculinas sésiles, rojizas, pequeñas y abundantes. Sépalos 5, estambres 10, filamentos cortos, anteras globosas. Flores femeninas rojizas, cáliz 5 sépalos, 5 pétalos, imbricados, estigmas tres, papilosos, ovario súpero globoso.

Fruto: Drupa, negra a la madurez obovoidea, con una semilla. Florece en agosto - setiembre. Ejemplares aislados o en grupos pequeños dispersos. Solamente se encuentran en el sector denominado Cruz del Carso.

Especie muy importante que debe protegerse por encontrarse en peligro de extinción.(Foto 4).

\section{Schinus molle L. "Molle, Falso pimiento".}

Árbol poligamo-dioico perennifolio de $2 \mathrm{~m}$ de altura. Copa amplia, tronco cilíndrico, por lo general torcido, corteza agrietada, áspera, de color pardo oscura, exuda una resina lechosa, pegajosa de color blanco brillante al secarse. Ramas delgadas, abundante follaje.

Hojas compuestas pinnadas. Folíolos alternosopuestos, sésiles lanceolados, margen entero o aserrados, de olor y sabor picante.

Inflorescencia: Panículas cónicas, miden entre 8$15 \mathrm{~cm}$ de largo. Fiores pequeñas, abundantes, cortamente pecioladas, de color blanco amarillento.

Fruto: Drupa esférica, exocarpio delgado, de color rozado-rojizo, brillante papiráceo. Mesocarpio delgado mucilaginoso. Endocarpio leñoso, duro, semilla redonda, color marrón a negro, sabor parecido al de la pimienta. Especie nativa de América tropical.

\section{Pluchea chingoyo (HBK) D.C. "Toñuz".}

Arbusto de 1,5 - $2 \mathrm{~m}$ de altura, muy ramificado. Hojas opuestas subsésiles oblongo lanceoladas, enteras glandulosas, muy resistente a sequía.

Capítulos numerosos en corimbos terminales. Flores dimorfas. Pappus piloso.

Fruto en aquenio angulado.

- Oriundo en Sudamérica.

\section{Tessaria integrifolia Ruiz et Pavon "Callacaza, Pájaro bobo".}

Arbusto de 1-1,5 m de altura, poco ramificado. Hojas simples, alternas, enteras, dentadas, grisáceastormentosas de $5-10 \mathrm{~cm}$ de largo.

Capítulos dispuestos en corimbos.

Pappus piloso. 
Aquenios gruesos subcilíndricos o turbinados.

- Originaria de América.

\section{Trixis paradoxa Cass.}

Arbusto de $0.50-1,20 \mathrm{~m}$ de altura, ramoso. Hojas simples alternas pecioladas o subsésiles, lanceoladas o elípticas, enteras o ligeramente aserradas.

Capítulos dispuestos en corimbos en el extremo de las ramas. Flores amarillentas, isomorfas. Pappus blanco.

Aquenio cilíndrico - linear.

- Oriundo de América.

\section{Baccharis aff lanceoiata "Chilca".}

Arbusto ramoso. Hojas lanceoladas, agudas en el ápice y alternas en la base, aserrada en la mitad superior del margen.

Capítulos dispuestos en corimbos, densos terminales. Flores con pappus blanco.

Aquenios glabros.

- Nativo de Sudamérica.

\section{Caesalpinia spinosa (Molina) Kuntze "Tara, Taya".}

Árbol nativo de América, de 2-6 $\mathrm{m}$ de altura, tronco con corteza rugosa, áspera, fisurada. Copa globosa irregular, poco densa. Ramas tiernas con espinas cónicas, cortas, fuertes. Hojas compuestas bipinnadas con 5-8 pares de folíolos opuestos. Pecíolo grueso. Folíolos lisos, glabros, verde oscuro cuando adultos. Con espinas en los peciolos y raquis.

Inflorescencia: Racimo de $6-20 \mathrm{~cm}$ de largo. Flores hermafroditas, cigomorfas, amarillo rojizas, pedíceladas.

Fruto: Vaina indehiscente, lineal, plana, de color rojizo - amarillento de 7-10 cm de largo. Contiene 810 semillas ovoides.

\section{Geoffroea decorticans (Hook \& Arn.) Burkart "Chañar".}

Árbol o arbusto xerófilo, caducifolio. Copa rígida. Corteza gris exfoliante. Hojas compuestas pinnadas, ramas pequeñas terminadas en espinas. Foliolos 3-13 por hoja alternos o subopuestos. Foliolo terminal mayor que los laterales.

Inflorescencia en racimo: Flores pediceladas, aparecen en primavera, antes que las hojas. Corola papilionácea, amarillo-rojiza.

Fruto: Drupa, semejante a una ciruela seca globosa u ovoide de color rojizo. Con 1-2 semillas fusiformes.

Nativo de América: Los frutos son comestibles y se utilizan como materia prima para elaborar dulces, bebidas y macerados.

9. Prosopis pallida (H.\& B. ex Willd.) H.B.K. "Algarrobo"

Árbol oriundo de partes áridas del Perú, Colombia y Ecuador. Puede medir 3-4 m o más de altura en el norte del país. Ramificado desde la base. Espinas en los nudos de $1-4 \mathrm{~cm}$ de longitud, o sin ellas.

Hojas bipinnadas 2-3 pares de pinnas. Foliolos opuestos en número de 11-14 pares, lineales, obtusos. Inflorescencia: racimos espiciformes, cilindricos $4-8 \mathrm{~cm}$. de longitud amarillo verdoso.

Fruto: Vaina de color amarillo, paja recta o algo curva 10-22 cm de longitud.

Semillas ovoides color pardo-brillosas. (Foto 3 ) especie en peligro de extinción.

\section{Prosopis chilensis (Molina) Stuntz emend. Burkart "Algarrobo".}

Nativo de las regiones áridas del sur del Perú, Bolivia, Chile central y norte de Argentina.

Árbol de 2-5 m de altura. Tronco corto, grueso. Corteza café-rojiza. Copa amplia, globosa. Ramas arqueadas, parcialmente espinosas, espinas caulinares de hasta $6 \mathrm{~cm}$ de largo. claros.

Hojas 1-3 yugas, con 13-28 pares de foliolos verde

Inflorescencia: Racimos espiciformes, cilindricos de 6-12 cm de longitud. Color verde claro amarillento.

Fruto: Legumbre subleñosa, coriácea suberrecta, falcada a veces estrangulada y con artejos de color amarillo-paja a café-rojizo con manchas purpúreas cuando muy seca, de $8-18 \mathrm{~cm}$ de longitud. Mesocarpio pulposo azucarado. Semillas ovoides o elíptico ovoides, lisas, café-amarillo o castaño-rojizo. Crece en el sur del Perú. Es altamente resistente a sequía y está en peligro de extinción. 


\section{Acacia huarango Ruiz "Huarango-guarango".}

Árbol o arbusto muy ramificado. Copa densa, piana y circular. Tronco grueso.

Hojas bipinnadas, estípulas transformadas en espinas rectas marrones de $1.5 \mathrm{~cm}$ de largo. Hasta 18 pares de pinas. Folíolos hasta 42 pares por pina.

Inflorescencia: Capítulos solos o agrupados en pares. Corola amarilla.

Fruto: Vaina comprimida hasta $10 \mathrm{~cm}$ de longitud, rectas ligeramente curvas con constricciones uniformes o desigualmente pronunciadas.

- Semillas lenticulares, marrones.

- Se lo encuentra en regiones tropicales y subtropicales de América.

\section{Acacia macracantha Humb. \& Bonpl. Exwilld "Espino" "Faique".}

Árbol pequeño, copa aparasolada, tronco cilíndrico, corteza gris, suavemente fisurada, ramas gruesas, frecuentemente blanquecina-tormentosas, algo pendulares.

Hojas compuestas bipinnadas. Cada pinna con $10-$ 60 pares de foliolos pequeños, diminutos de color verde oscuro en el haz, verde-claro en el envés. Espina estipular delgada $1-3 \mathrm{~cm}$ de longitud.

Inflorescencia: Capítulos esféricos vistosos, de color amarillo-anaranjado, formando racimos simples o compuestos.

Frutos: Vainas puberulentas rectas o curvadas de 5-7 cm de longitud, indehiscentes, negruzcas.

Semillas: ligeramente ovaladas, color marrón brillante. Entre 3-10 semillas por vaina.

Oriundo de las zonas tropicales y subtropicales desérticas y semiáridas de América.

\section{REFERENCIAS BIBLIOGRÁFICAS}

DIAAS CELIS, A. Los aigarrobos.

VARIOS (1985). Estado actual del conocimiento sobre Prosopis tamarugo FAO. Universidad de Tarapacá. Corporación Nacional Forestal - Chile.

ZEGARRA, R. (1993). "La vegetación desértica perenne de

\section{Acacia aromo Gill ex Hook et Arn "Aromo".}

Árbol o arbusto de 2-5 m de altura, espinoso. Ramificación amplia y plana. Estipulas hasta $5 \mathrm{~cm}$ de longitud. Hojas bipinnadas, pinas de hasta 20 pares, foliolos en número de hasta 36 pares por pinna.

Inflorescencia: Flores agrupadas en capítulos esféricos amarillo-anaranjados, pedunculadas, solitarias o en número de dos.

Fruto: Vainas cilindricas moniliformes de color castaños hasta $15 \mathrm{~cm}$ de largo. Semillas lenticulares marrón-castañas.

Especie fraganciosa originaria de las zonas áridas y semiáridas de Chile, Argentina y Perú. (Foto 5). En peligro de extinción.

14. Waltheria ovata Cav. "Membrillejo, ancoacha, cimarrona, palo negro".

Subarbusto erguido o postrado de $1-1,5 \mathrm{~m}$ de altura. Ramificado. Cubierto por tricomas estrellados.

Hojas simples, alternas, pecioladas, ovoides, dentado-aserradas pubescentes en el haz, color verdeplomizo.

Inflorescencia en glomérulos a lo largo de los ejes que nacen de la axila de las hojas.

Flores amarillas.

Fruto: capsular coriáceo con dos semillas pequeñas ovoides, pardas. Especie probablemente nativa de América. (Foto 2).

\section{CONCLUSIONES}

De las 14 especies arbóreas y subarbustivas registradas y estudiadas en el valle de Cinto, cuatro de ellas se encuentran en muy baja frecuencia y en peligro de extinción, por lo que deben dictarse las medidas de protección y conservación ertementes.

Tacna: Estudio biosistemático y sus recursos naturales".Revista Nueva Imagen, $N^{0} 3$, U.N.J.B.G., Tacna - Perú.

ZEGARRA, R. (1999). "Vegetación de torrenteras en el Departamento de Tacna". Revista Clencia y Desarrollo. Tacna - Perú. 
Especies arbóreas y arbustivas más frecuentes en el Valle de Cinto.

\begin{tabular}{|c|l|c|c|c|}
\hline$N^{\circ}$ & \multicolumn{1}{|c|}{ ESPECIE } & N COMUN $^{\circ}$ & FAMILIA & CONSISTENCIA \\
\hline 1 & Haplorhus peruviana & Jassi, molle, carza & Anacardiaceae & Árbol \\
\hline 2 & Schinus molle & Molle & Anacardiaceae & Árbol \\
\hline 3 & Pluchea chirgoyo & Toñuz & Asteraceae & Arbusto \\
\hline 4 & Tessaria integrifolia & Callaca, Pájaro lobo & Asteraceaea & Arbusto \\
\hline 5 & Trixis paradoxa & & Asteraceae & Arbusto \\
\hline 6 & Baccharis aff. lanceoiata & Chilca & Asteraceae & Arbusto \\
\hline 7 & Caesalpinia spinosa & Tara & Fabaceae & Árbol \\
\hline 8 & Geoffroea decorticans & Chañar & Fabaceae & Arbusto \\
\hline 9 & Prosopis pallida & Algarrobo & Fabaceae & Arbusto \\
\hline 10 & Prosopis chilensis & Algarrobo & Fabaceae & Arbusto \\
\hline 11 & Acacia huarango & Huarango & Fabaceae & Arbusto \\
\hline 12 & Acacia macracantha & Huarango & Fabaceae & Arbusto \\
\hline 13 & Acacia aroma & Acacia & Fabaceae & Árbol \\
\hline 14 & Waltheria ovata & Membrillejo & Sterculiaceae & Arbusto \\
\hline
\end{tabular}

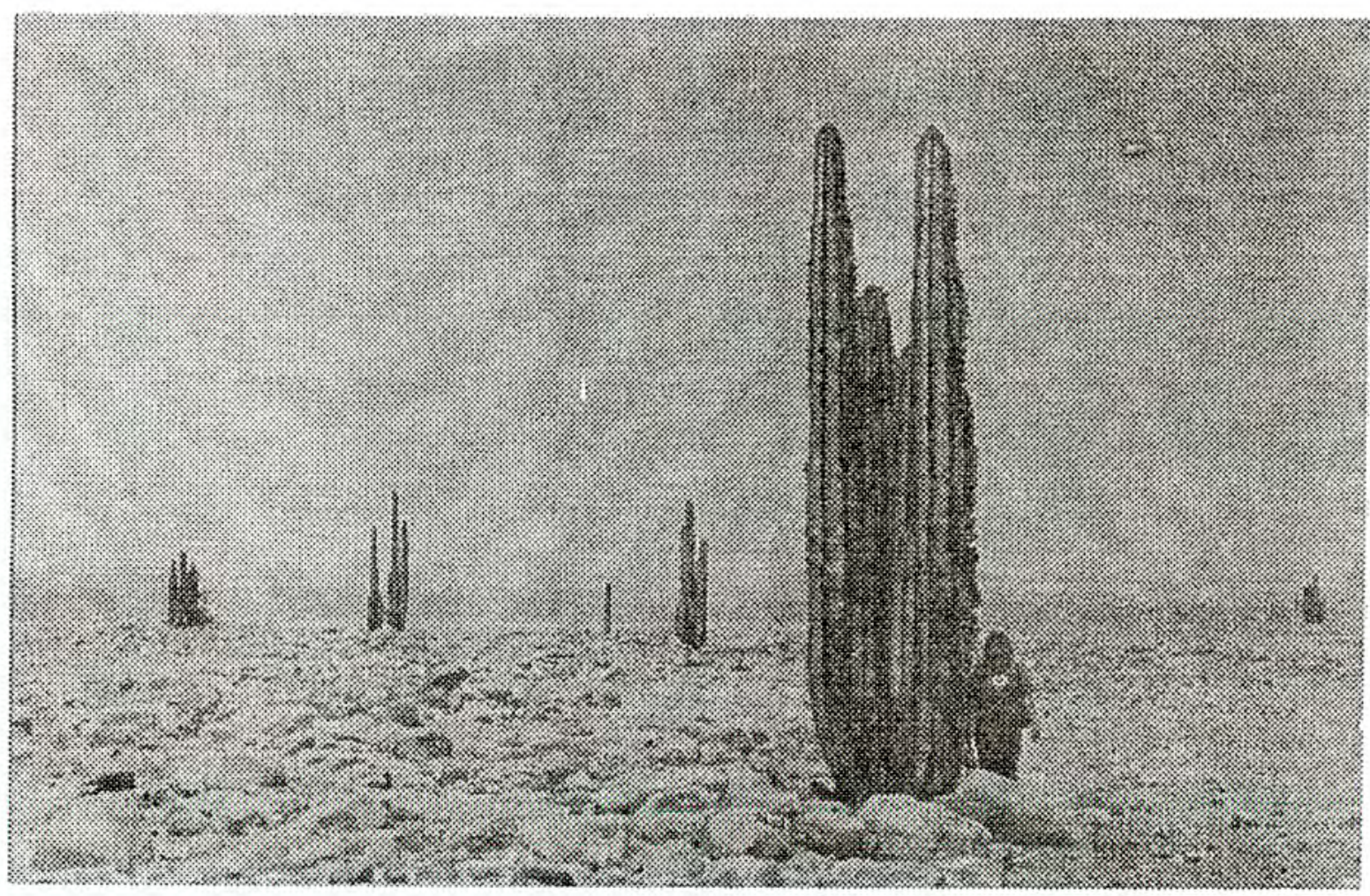

Foto 1. Entre Camiara, Puquio y Tomasiri, al lado este se encuentra una comunidad de Neoraimondia arequipensis "Gigantón". 


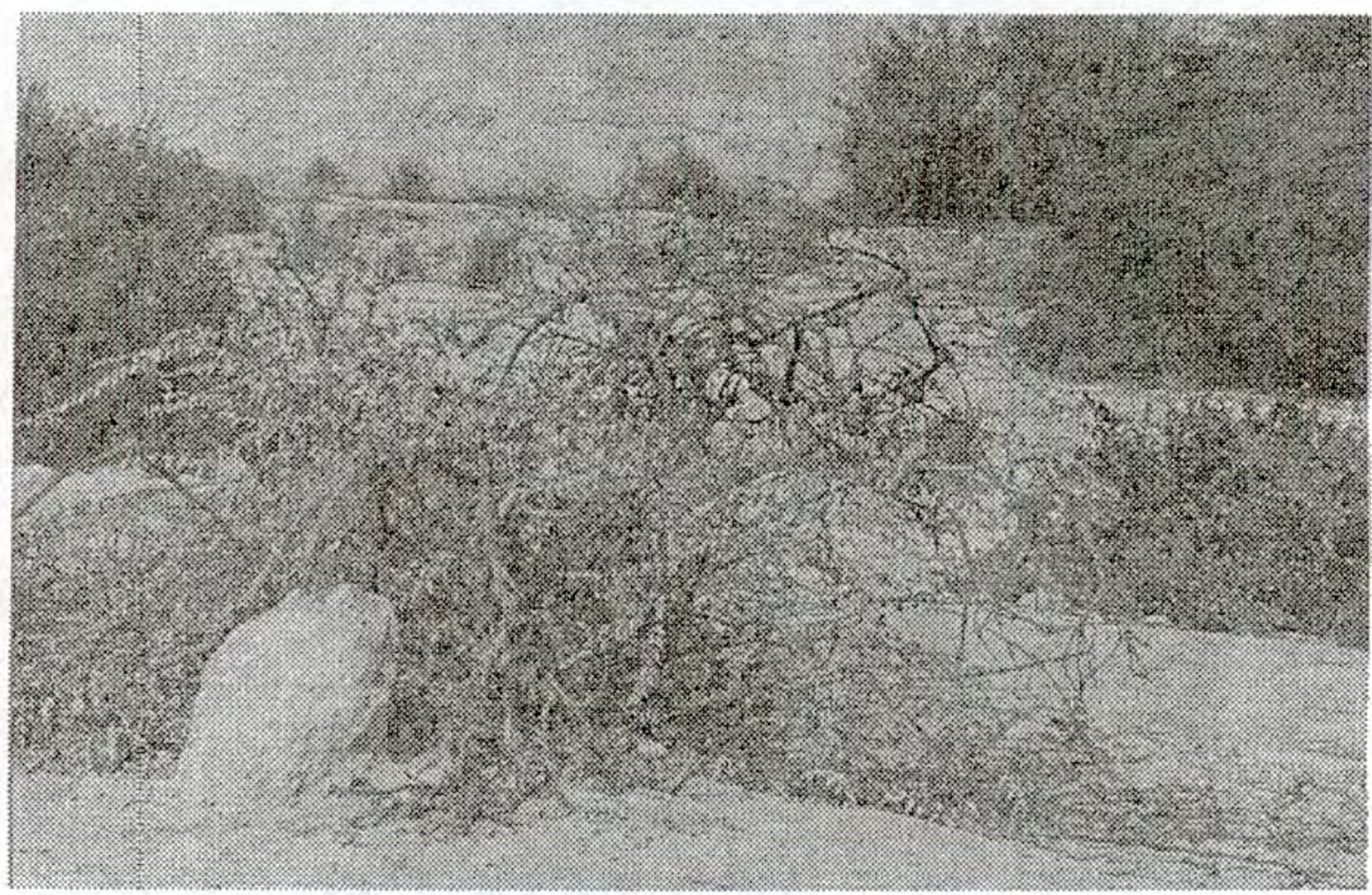

Foto 2. Waltheria ovata: "Ancoacha" "Membrillejo" "Cimarrona o palo negro". Especie que crece en cauce de rios secos.

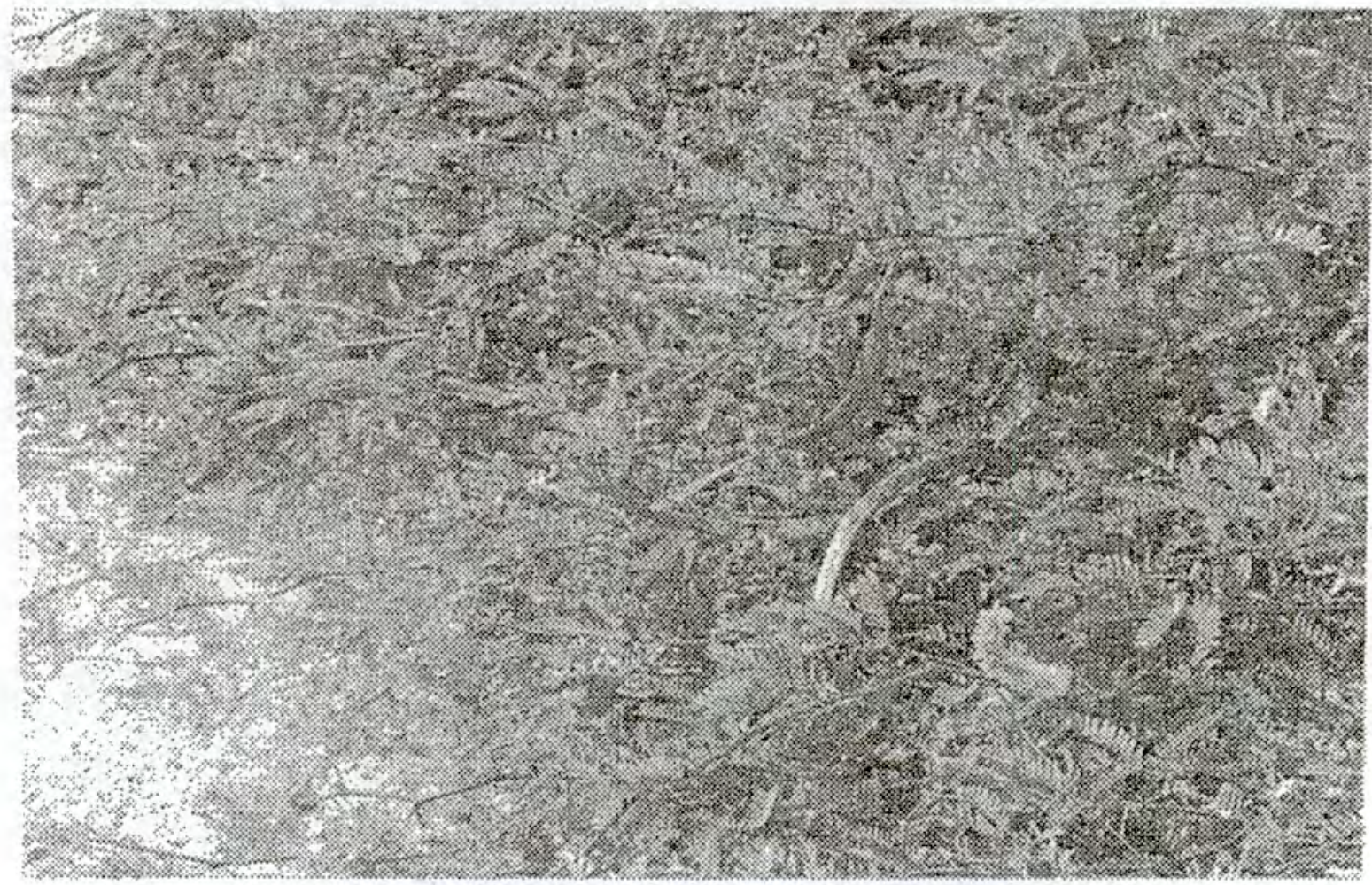

Foto 3. Prosopis pallida: "Algarrobo". Especie arbustiva de gran valor forestal. 


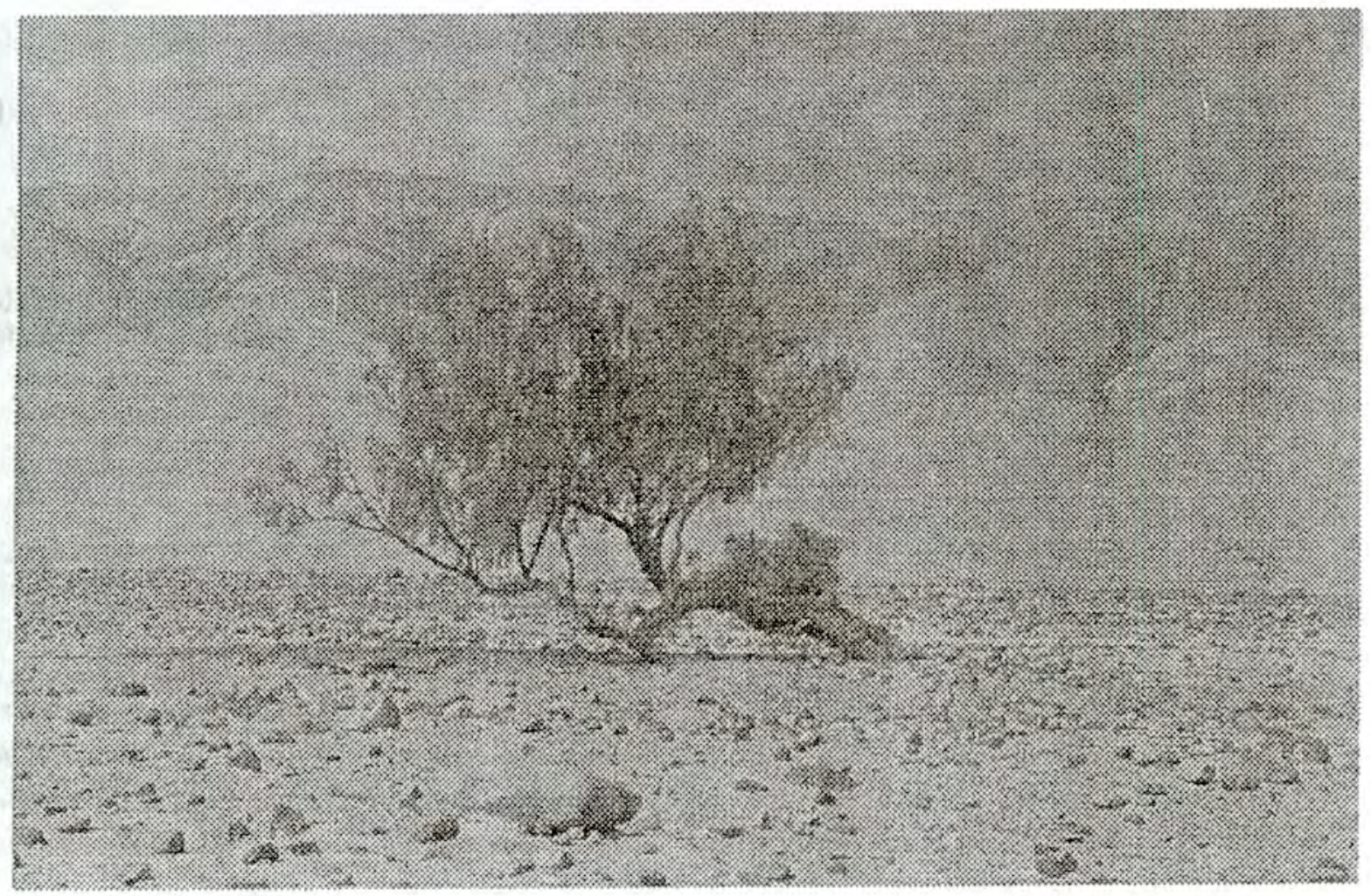

Foto 4. Haphorus perwviana: "Jassi, carza". Especie arbórea rara y endémica de remarcable adaptación a las condiciones del Valle desértico de Cinto.

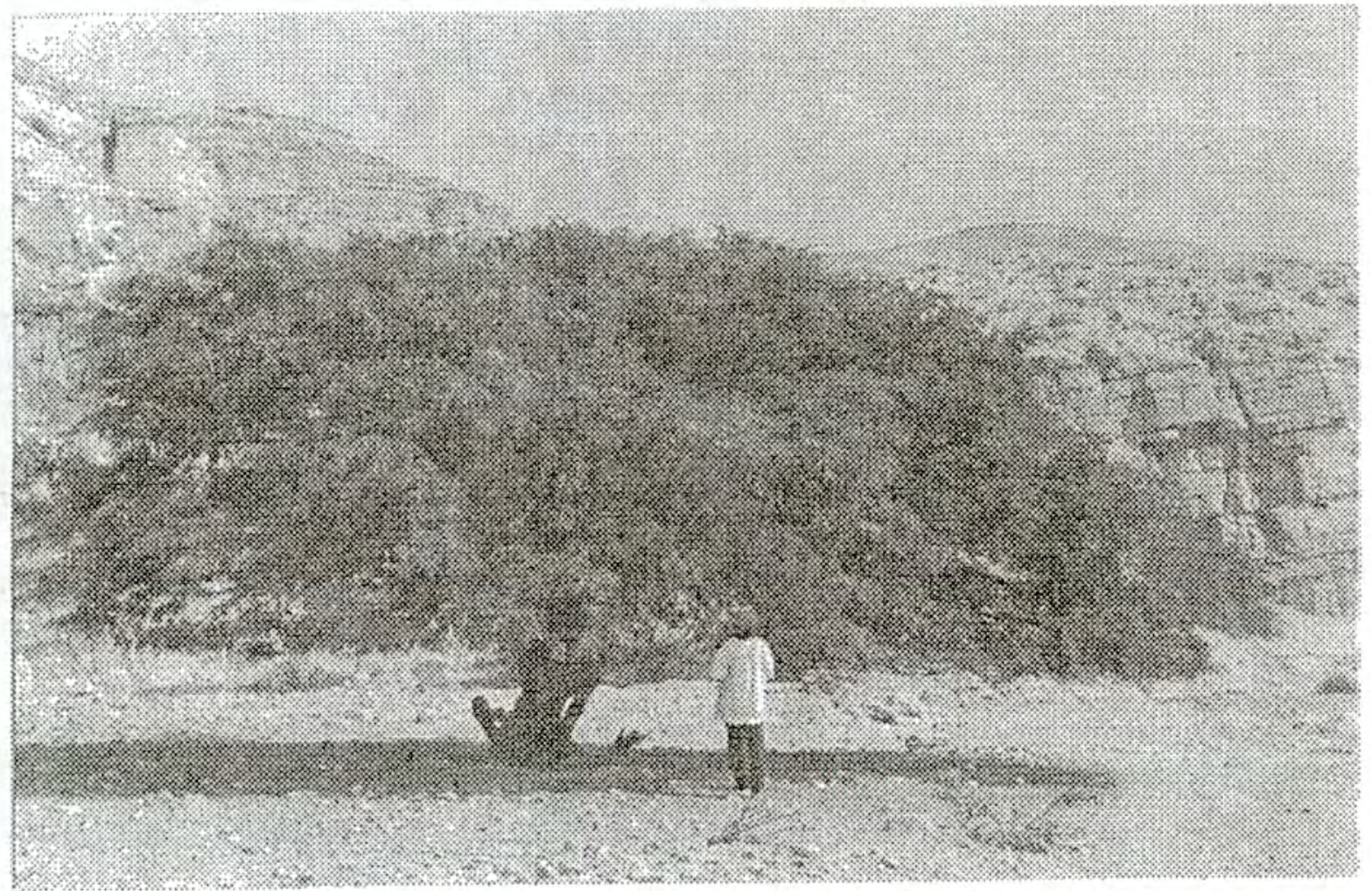

Foto 5. Acacia aromo. "Huarango". La especie más frondosa de las zonas desérticas del sur del Perú y norte de Chile. 